\title{
Real-time detection and management of chronic illnesses
}

Chronic illnesses, also known as noncommunicable diseases, has increasingly burdened healthcare systems and individuals worldwide (1). Three in five global deaths are due to cardiovascular disease, cancer, chronic lung diseases and diabetes (1). In 2001, chronic illnesses accounted for approximately $60 \%$ of the 56.5 million total reported deaths in the world and about $46 \%$ of the global burden of disease (2). The proportion of the burden of chronic illnesses is expected to increase to $57 \%$ by 2020 (3). For example, the clinical expenses of chronic illnesses in the United States are projected to reach $80 \%$ of the total medical costs, and more than 150 million people may have chronic illnesses by 2020 (4). Thus, reducing the prevalence and burden of chronic illnesses is imperative and a global priority.

Chronic illnesses share a myriad of characteristics: no medical or surgical cure at present, a constellation of symptoms and signs, a need for a long-term care, and episodes of exacerbated condition that require timely intervention. Early detection of health changes are keys to promoting health and function of people with chronic illnesses $(5,6)$. Symptoms and signs are major indicators of health changes for people with chronic illnesses as symptoms and signs denote abnormal changes occurring in body functioning or manifestations of exacerbated disease condition (7). Technology advancements such as mHealth (i.e., health care supported by mobile systems and devices) has made real-time detection of health changes a reality to allow individuals to report of symptoms and signs or other health indicators (e.g., heart rate/patterns, blood pressure) in real-time when they experience the changes (6). Real-time detection of health changes is essential in chronic illness management to improve health outcomes, quality of life, and cost-effective health care.

The long-term and incurable nature of chronic illnesses as well as the need for continuous monitoring of symptoms and sighs have inspired and continue inspiring ongoing technology advancements to optimize chronic illness management and detection of signs and symptoms to prevent mortality, exacerbations, emergency visits, unscheduled hospital admissions, and disability $(8,9)$. Technology advancements such as mHealth have increasingly being used to promote chronic illness management for communication, data collection, patient monitoring, patient and provider education in a variety of healthcare settings, such as in clinics or outside clinical facilities and in-patient health care $(10,11)$. For example, prioritization of care for healthcare providers can be facilitated in the process of identifying patients with the most urgent needs through the use of mHealth in clinic or outside clinical and in-patient settings (12). Real-time detection of the health changes is the key for care prioritization. Therefore, technology developments that allow not only real-time report of symptoms and signs but also integrate prioritization process, and delivery of care can help healthcare providers to immediately discern which patients need immediate care. This allows healthcare providers save time in collecting or retrieving needed information from huge medical records but focus on delivering quality care. mHealth devices, such as wearable technologies and apps, provide opportunities for continuous real-time monitoring of symptoms and signs, self-management behaviors, delivery of care, and connecting patients with providers outside of health care facilities (13). Such examples are featured in this special issue.

The emerging evidence shows the positive impact of mHealth on chronic illness management and detection. Yet, more work has to be done. Systematic reviews indicate that mHealth often includes a single technology or a single chronic illness or a specific mHealth application or device $(8,14)$. It should be noted that this focused nature of mHealth may reflect the complexity of chronic illnesses which may not allow a single development of a mHealth application for all chronic illnesses. For example, although chronic illnesses share the phenotypical characteristics of a constellation of symptoms and sighs, each chronic illness has its own cardinal symptoms and signs that denote health changes for immediate care. mHealth focusing on real-time detection and management of a given chronic illness may be more effective and lessen the burden of people with chronic illnesses. The focused nature of mHealth may also reflect current developmental stage of mHealth for chronic illness management. With sufficient evidence through rigorous testing on mHealth for each chronic illness in terms of efficacy, feasibility, implementation and effectiveness, a global mHealth infrastructure consisting of evidence-based mHealth for management of each chronic illness can be fashioned in future. The popularity, availability, portability, and technological capacity of mobile phones and mHealth systems and devices have enormous potential to impact chronic illness management around the world by reaching people with chronic illnesses without geographic limitations. 


\section{Acknowledgments}

Funding: None.

\section{Footnote}

Provenance and Peer Review: This article was commissioned by the editorial office, mHealth for the series "Real-Time Detection and Management of Chronic Illnesses". The article did not undergo external peer review.

Conflicts of Interest: The author has completed the ICMJE uniform disclosure form (available at http://dx.doi.org/10.21037/ mhealth-2020-2). The series "Real-Time Detection and Management of Chronic Illnesses" was commissioned by the editorial office without any funding or sponsorship. MRF served as the unpaid Guest Editor of the series.

Ethical Statement: The author is accountable for all aspects of the work in ensuring that questions related to the accuracy or integrity of any part of the work are appropriately investigated and resolved.

Open Access Statement: This is an Open Access article distributed in accordance with the Creative Commons AttributionNonCommercial-NoDerivs 4.0 International License (CC BY-NC-ND 4.0), which permits the non-commercial replication and distribution of the article with the strict proviso that no changes or edits are made and the original work is properly cited (including links to both the formal publication through the relevant DOI and the license). See: https://creativecommons.org/ licenses/by-nc-nd/4.0/.

\section{References}

1. Non communicable diseases [Internet]. [cited 2020 Aug 4]. Available online: https://www.who.int/news-room/fact-sheets/detail/ noncommunicable-diseases

2. GBD 2015 Mortality and Causes of Death Collaborators. Global, regional, and national life expectancy, all-cause mortality, and cause-specific mortality for 249 causes of death, 1980-2015: a systematic analysis for the Global Burden of Disease Study 2015. Lancet 2016;388:1459-544.

3. WHO I Nutrition [Internet]. WHO. World Health Organization; [cited 2020 Aug 4]. Available online: http://www.who.int/ nutrition/en/

4. Nguyen TT, Khosravi A, Creighton D, et al. Classification of healthcare data using genetic fuzzy logic system and wavelets. Expert Syst Appl 2015;42:2184-97.

5. Beaglehole R, Epping-Jordan J, Patel V, et al. Improving the prevention and management of chronic disease in low-income and middle-income countries: a priority for primary health care. Lancet 2008;372:940-9.

6. Fu MR, Wang Y, Li C, et al. Machine learning for detection of lymphedema among breast cancer survivors. Mhealth 2018;4:17.

7. Fu MR, LeMone P, McDaniel RW. An integrated approach to an analysis of symptom management in patients with cancer. Oncol Nurs Forum 2004;31:65-70.

8. van Dyk L. A review of telehealth service implementation frameworks. Int J Environ Res Public Health 2014;11:1279-98.

9. Parekh AK, Goodman RA, Gordon C, et al. Managing multiple chronic conditions: a strategic framework for improving health outcomes and quality of life. Public Health Rep 2011;126:460-71.

10. Palozzi G, Binci D, Appolloni A. E-health and co-production: Critical drivers for chronic diseases management. In: Service Business Model Innovation in Healthcare and Hospital Management, Springer, 2017:269-96.

11. de Jongh T, Gurol-Urganci I, Vodopivec-Jamsek V, et al. Mobile phone messaging for facilitating self-management of longterm illnesses. Cochrane Database Syst Rev 2012;12:CD007459.

12. Mohammed KI, Zaidan AA, Zaidan BB, et al. Real-Time Remote-Health Monitoring Systems: a Review on Patients Prioritisation for Multiple-Chronic Diseases, Taxonomy Analysis, Concerns and Solution Procedure. J Med Syst 2019;43:223. 
13. Patel S, Park H, Bonato P, et al. A review of wearable sensors and systems with application in rehabilitation. J Neuroeng Rehabil 2012;9:21.

14. van Velthoven MH, Brusamento S, Majeed A, et al. Scope and effectiveness of mobile phone messaging for HIV/AIDS care: a systematic review. Psychol Health Med 2013;18:182-202.

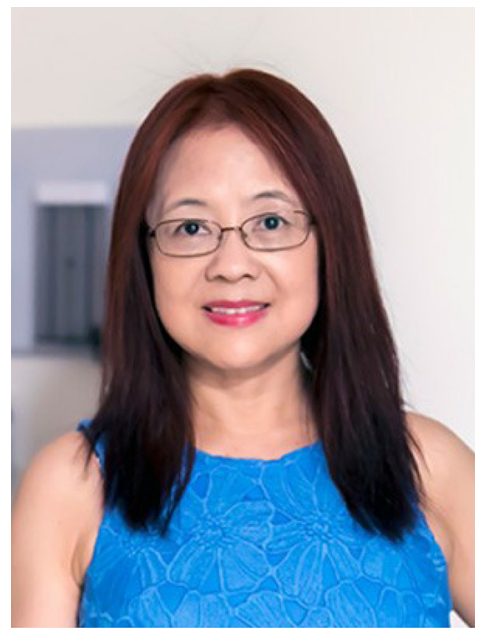

Mei R. Fu

Mei R. Fu, PhD, RN, FAAN

Barry Family \& Goldman Sachs Endowed Professor, Boston College William F. Connell School of Nursing, Chestnut Hill, MA, USA. (Email: mei.r.fu@bc.edu)

Received: 05 August 2020; Accepted: 18 August 2020; Published: 20 January 2021. doi: $10.21037 /$ mhealth-2020-2

View this article at: http://dx.doi.org/10.21037/mhealth-2020-2

doi: $10.21037 /$ mhealth-2020-2

Cite this article as: Fu MR. Real-time detection and management of chronic illnesses. mHealth 2021;7:1. 